\title{
A Time-Resolved Fluorescence Immunoassay for the Measurement of Testosterone in Saliva: Monitoring of Testosterone Replacement Ther- apy with Testosterone Buciclate
}

\author{
Matthias Tschöp ${ }^{1}$, Hermann M. Behre², Eberhard \\ Nieschlag' ${ }^{2}$, Regina A. Dressendörfer ${ }^{1}$ and \\ Christian J . Strasburger ${ }^{1}$ \\ ${ }^{1}$ AG Neuroendokrinologie, Medizinische Klinik, Klinikum \\ Innenstadt der Ludwig Maximilians Universität München, \\ München, Germany \\ 2 Institut für Reproduktionsmedizin der westfälischen \\ Wilhelms Universität, Münster, Germany
}

Monitoring of testosterone replacement therapy requires a reliable method for testosterone measurement. Determination of salivary testosterone, which reflects the hormone's biologically active plasma fraction, is a superior technique for this purpose. The aim of the present study was to establish a new sensitive time-resolved fluorescence immunoassay for the accurate measurement of testosterone levels in saliva and to validate it by monitoring testosterone replacement therapy in eight hypogonadal men.

A clinical phase I- study with the new ester testosterone buciclate was performed to search for new testosterone preparations to produce constant serum levels in the therapy of male hypogonadism. After two control examinations eight male patients with primary hypogonadism were randomly assigned to two treatment groups $(n=2 \times 4)$ and given single doses of either $200 \mathrm{mg}$ (group I) or $600 \mathrm{mg}$ (group II) testosterone buciclate intramuscularly. Saliva and blood samples were obtained 1, 2, 3, 5 and 7 days post injection and then weekly for three months.

The time-resolved fluorescence immunoassay for salivary testosterone shows a detection limit of $16 \mathrm{pmol} / \mathrm{l}$, an intra-assay CV of $8.9 \%$ (at a testosterone concentration of 302 pmol/l), an inter-assay CV of $\mathbf{8 . 7 \%}$ (at a testosterone concentration of $305 \mathrm{pmol} / \mathrm{l}$ ) and a good correlation with an established radioimmunsassay of $r=0.89$. The sample volume required by this method is only $\mathbf{1 8 0} \mu \mathrm{l}$ for extraction and duplicate determination. The assay procedure requires no more than three hours.

In group I (200 mg) testosterone did not increase to normal levels either in saliva or in senum. However, in group II, androgen levels increased significantly and were maintained in the nomal range for up to 12 weeks with maximal salivary testosterone levels of $303+18 \mathrm{pmol} / \mathrm{I}$ (mean $\pm \mathrm{SE}$ ) and maximal testosterone levels of $13.1 \pm 0.9 \mathrm{nmol} / \mathrm{I}$ (mean $\pm S E$ ) in serum in study week 6 and 7.

The time-resolved fluorescence immunoassay for salivary testosterone provides a useful tool for monitoring androgen status in men and women and is well suited for the follow-up of testosterone replacement therapy on an outpatient basis. The long-acting ester testosterone buciclate is a promising agent for substitution therapy of male hypogonadism and in combination with testosterone monitoring in saliva offers an interesting new perspective for male contraception.

Key words: Testosterone; Saliva; Testosterone buciclate; Fluorescence immunoassays; Biotin.

\section{Introduction}

In monitoring the function of steroid-producing organs, the quantification of steroid hormones in saliva is a useful, non-invasive approach for the assessment of biologically active hormone concentrations (1-3). The appearance in saliva of steroids such as testosterone is flow rate-independent and is caused by their free diffusion from blood plasma to saliva through the epithelial cells of the salivary gland $(2,4,5)$, which is comparable with the physiological process of entering target cells. It is likely, therefore, that the non-sex hormone-binding globulin(SHBG)-bound fraction is readily available to target cells physiologically active, and that this fraction is identical with salivary testosterone (6-8). In plasma, the non-SHBG-bound fraction mainly represents the unbound fraction (1-3\%) and the albumin-bound hormone fraction $(20-80 \%)$ in plasma $(9,10)$. Because of the non-invasive and stress-free technique of sample collection as well as the ease of multiple sampling by the patient himself, salivary hormone assays are being used increasingly in psychological $(11,12)$, anthropological $(13,14)$, and field studies (15). From a clinical point of view, salivary testosterone results not only seem to be of greater diagnostic use in hirsutism than any of the currently used serum androgen parameters (16), but also seem to be well suited for monitoring testosterone replacement therapy.

Traditionally, salivary testosterone has been measured by immunoassays using ${ }^{3} \mathrm{H}$ - or ${ }^{125}$-labelled testosterone-derivatives as tracers. In order to exploit the exceptional affinity of the avidin-biotin system $\left(K_{a}=10^{15}\right.$ $\mathrm{M}^{-1}$ ) (17), a low molecular weight testosterone-biotin conjugate for use as a tracer in a testosterone immunoassay was synthesized. With this stable tracer as a tool, a time-resolved fluorescence immunoassay (TRFIA) was established as a new, non-isotopic approach to the measurement of salivary testosterone.

Commonly used testosterone esters, given either intramuscularly or orally, correct many symptoms of testosterone deficiency, but their pharmacokinetics are 
still unfavourable. The potential application of androgens to substitution therapy of aging men (18) and to the surveillance of male contraception (19, 20), however, makes the increasing use of androgen preparations likely. To assess the pharmacokinetics and pharmaco-dynamics of the new WHO and National Institute of Health $(\mathrm{NIH})$ ester, testosterone buciclate, in hypogonadal men, a clinical phase I-study was performed $(21,22)$.

This study was monitored by the measurement of salivary testosterone with the newly established TRFIA.

\section{Subjects and Methods}

Establishment and validation of the TR-FIA for the measurement of salivary testosterone

Synthesis of a testosterone 3-(O-carboxymethyl)-oxime (testosterone-3-CMO)-biotin conjugate

Fifty $\mu \mathrm{mol}(18.075 \mathrm{mg}$ ) of testosterone-3-CMO (Sigma, Deisenhofen, Germany, Cat. No. T-8390) were dissolved in $200 \mu \mathrm{l}$ of dry, amine free $\mathrm{N}, \mathrm{N}^{\prime}$-dimethylsulfoxide (DMSO) (Merck, Darmstadt, Germany, Cat. No. 2952). Equimolar amounts (6.31 $\mathrm{mg}$ and $11.18 \mathrm{mg}$ respectively) of $\mathrm{N}$-hydroxysuccinimide (NHS) (Sigma, Cat. No. H-7377) and N,N'-dicyclohexylcarbodiimide (Sigma, Cat. No. D-3128) were dissolved each in $50 \mu \mathrm{l}$ of DMSO and added to the testosterone-3-CMO. This reaction mixture was left at room temperature in the dark for 24 hours during which time the testosterone-3-CMO was converted into its NHS ester, and needle-like crystals of dicyclohexyl urea appeared. For coupling of the testosterone-N-hydroxysuccinimide ester to biotin (23), $50 \mu \mathrm{mol}(18.66 \mathrm{mg})$ of biotinamidocaproyl hydrazide (Sigma, Cat. No. B-3770), were dissolved in $200 \mu \mathrm{l}$ of DMSO. The biotin derivative was added to the reaction mixture which was left at room temperature for another 24 hours in the dark. The proposed mechanism of reaction and structure of the final product are shown in Figure 1 (24). The course of the reaction was monitored by thin layer chromatography under UV-light.

\section{Purification of the testosterone-3-CMO-biotin conjugate}

Aliquots of this reaction mixture were applied to a $10 \times 400 \mathrm{~mm}$ Trisacryl GF 05 M (Serva, Heidelberg, Germany, No. 67010) column after $1: 10(\mathrm{v} / \mathrm{v})$ dilution in column buffer $(50 \mathrm{mmol} / \mathrm{l}$ Tris- $\mathrm{HCl}$ adjusted to $\mathrm{pH} 7.8$ with $1 \mathrm{~mol} / \mathrm{HCl}$ ) using fast performance liquid chromatography (FPLC). The elution pattern of the column showed two well-separated peaks.

\section{Characterization of the testosterone-3-CMO-biotin conjugate}

The testosterone content of the fractions was analyzed by a commercially available radioimmunoassay (RIA-mat Testosteron, Byk Sangtec Diagnostica GmbH, Dietzenbach, Germany, No. 322.451). Testosterone concentrations corresponded to the absorbance at $254 \mathrm{~nm}$ of the column eluate. In addition the fractions were tested as tracer for maximal binding and displacement by a $6.93 \mathrm{nmol} / \mathrm{l}$ testosterone standard. Determinations were performed in duplicate, and the ratio between the signal obtained at maximal binding and the displacement by the $6.93 \mathrm{nmol} / \mathrm{l}$ standard was calculated. The second of the two peaks at $254 \mathrm{~nm}$ showed the highest binding ratio and apparently contained the testosterone-biotin conjugate, while the first peak contained mainly uncoupled testosterone. Finally, the biotin content of the fractions was measured with an in-house TR-FIA for biotin determination and confirmed the previous findings by showing significant amounts of biotin in the second peak of the elution pattern.

\section{Testosterone antiserum}

Testosterone antiserum was kindly provided by Prof. F. Bidlingmaier (Bonn, Germany). Specificity of the antiserum was determined by addition of increasing amounts of cross-reacting steroids as the unknown sample in the immunoassay described here. The doses of testosterone and cross-reacting steroid hormone effectively displacing $50 \%$ of the tracer from the antibody (ED-50) were compared and the respective concentrations were expressed as ED-50 (testosterone): ED-50 (cross-reacting steroid) $\times 100$ (\%).<smiles>NNC(=O)CCCCCNC(=O)CCCCC1SCC2NC(=O)NC21</smiles><smiles></smiles>

Biotinamidocaproyl hydrazide

Testosterone-3-CMO NHS active ester<smiles>CN=C1C=C2CCC3C(CCC4(C)C(O)CCC34)C2(C)CC1</smiles>

Testosterone-3-CMO-biotinylhydrazide

Fig. 1 Pathway of synthesis and proposed chemical structure of the testosterone-biotin tracer conjugate. 


\section{Saliva sampling}

Saliva samples were taken at two control examinations, shortly before and 1 hour and 1, 2, 3, 5, 7 days after testosterone buciclate injection, and then weekly up to week 16 .

Of three existing types of saliva sampling devices ("Salivette", Sarstedt, Nümbrecht, Germany) only one type (No. 51.1534.002) can be used without a positive bias in the analytical results $(25,26)$. This type of "salivette" consists of a $40 \times 9 \mathrm{~mm}$ non-glued polyester wool swab wrapped in polypropylene film, an inner and an outer polystyrene tube. For sampling, ten minutes after rinsing the mouth with water (but no tooth brushing, to avoid gingival microlesions) (27), the polyester wool swab is kept in the mouth or chewed on for 0.5- $2 \mathrm{~min}$. The swab is then transferred to the inner of the two polystyrene tubes and the sample is frozen. Unpreserved saliva samples stored unrefrigerated have been shown to yield satisfactory results for male subjects, but lead to increased measured concentrations for female subjects (28). In our own experiments a storage time up to three months at room temperature did not have significant influence on the salivary testosterone results. Storage time of frozen samples does not seem to affect the reliability of the measurement of salivary steroids (25). By centrifugation of the thawed samples prior to analysis, the salivary liquid is transferred to the outer tube. Saliva samples which on inspection are contaminated with blood are excluded from the analysis (29).

\section{Assay design}

Affinity purified swine anti-rabbit immunoglobulin (Dako, Hamburg, Germany, No. Z 400) was immobilized on to microtitre plates (Maxisorp, Nunc, Roskilde, Denmark, No. 4-42404) at $200 \mathrm{ng}$ per well in $200 \mu \mathrm{l}$ of $50 \mathrm{mmol} / \mathrm{l}$ trisodium phosphate adjusted to $\mathrm{pH} 9.6$ with $1 \mathrm{~mol} / \mathrm{l} \mathrm{HCl}$. These plates can be stored at $4{ }^{\circ} \mathrm{C}$ in the coating buffer up to three months without apparent loss of binding activity for testosterone and the testosterone-biotin conjugate. After an incubation for at least 12 hours plates were washed three times in an automatic plate washer (DELFIA platewash, Pharmacia, Uppsala, Sweden, No. 1296024), then $200 \mu \mathrm{l}$ of the antigen-specific testosterone antiserum diluted 1:100000 in assay buffer $(50 \mathrm{mmol} / \mathrm{l}$ Tris- $\mathrm{HCl}$, $150 \mathrm{mmol} / \mathrm{l} \mathrm{NaCl}, 5 \mathrm{~g} / \mathrm{l}$ bovine serum albumin (BSA) (SIGMA, Cat. No. A-7906), $0.5 \mathrm{~g} / \mathrm{l}$ bovine $\gamma$-globulin (SIGMA, Cat. No. G-7516), 0.5 g/l NaN 3 (Merck, Cat. No. 6688), 0.1 g/l Tween 40 (Sigma, Cat. No. P 1504), and 7.87 mg/l Diethylenetriaminepentaacetic acid (DTPA) (Sigma, Cat. No. D-6518) adjusted to $\mathrm{pH} 7.7$ with $1 \mathrm{~mol} / \mathrm{l} \mathrm{HCl}$ ) were added and stored for 24 hours to two months at $4{ }^{\circ} \mathrm{C}$. Testosterone standards were prepared by diluting an ethanolic, photometrically calibrated stocksolution of testosterone $(260 \mathrm{mg} / \mathrm{l})$ in "artificial saliva" containing (per $100 \mathrm{~g})$ : sorbitol $(3.0 \mathrm{~g})$, potassium chloride $(0.150 \mathrm{~g})$, sodium chloride $(0.085 \mathrm{~g})$, calcium chloride dihydrate $(0.015 \mathrm{~g})$, hydroxyethyl cellulose $(0.120 \mathrm{~g})$ and water up to $100.0 \mathrm{~g}$. The antibody-coated plates were washed and $50 \mu \mathrm{l}$ of standard or extracted sample were pipetted to the bottom of the microtitre plate wells. Subsequently, $50 \mu$ l of the testosterone-biotin conjugate as the tracer and $100 \mu \mathrm{l}$ of assay buffer were added. Incubation was allowed to proceed for two hours at ambient temperature on a horizontal microtitre plate shaker (DELFIA Plateshake, Pharmacia, No. 1296-001).

\section{Endpoint determination}

The incubation was terminated by washing the plates three times, and 20 ng of streptavidin-europium conjugate (Pharmacia, No. 1244-360) diluted in $200 \mu$ lassay buffer were added to each well. The reaction was allowed to proceed for
30 minutes on a horizontal shaker. After a 6-fold wash step, "enhancement solution" (Pharmacia, No. 1244-105) was added, which transforms the europium coupled to streptavidin into a highly fluorescent complex (30). TR-FIA measurement was carried out in a 1232 DELFIA fluorometer (Pharmacia, No. 1232-002, Wallac, Turku, Finland).

\section{Reference radioimmunoassay}

The established RIA for salivary testostererone, with which the TR-FIA was compared, requires $1 \mathrm{ml}$ to $3 \mathrm{ml}$ saliva for extraction with ether and salivary testosterone determination (31).

For the RIA an anti-testosterone-3-CMO-BSA-serum was used and the only steroid which significantly cross-reacted was $5 \alpha$-dihydrotestosterone (60\%). Sensitivity of the saliva RIA, taken as the value on the standard curve at two standard deviations below the maximum specific binding, was $35 \mathrm{pmol} / \mathrm{l}$. The intra-and inter-assay coefficients of variation were $3.7 \%$ and $13.8 \%$, respectively.

\section{Sample preparation}

In order to eliminate matrix interference, saliva samples $(180 \mu \mathrm{l})$ were extracted by addition of $1.8 \mathrm{ml}$ of dichloromethane (Merck, Darmstadt, Germany) containing $50 \mathrm{mg} / \mathrm{l}$ polyethyleneglycol 10000 (Merck, Darmstadt, Germany). Samples were mixed for 15 minutes on a horizontal shaker. The samples were then left unagitated for 10 minutes to allow phase separation. Subsequently, $1.65 \mathrm{ml}$ of the organic solvent was carefully removed and evaporated using a water bath and the residue was redissolved in the "artificial saliva" (165 $\mu \mathrm{l})$. Recovery of this extraction step was determined by measurement of control samples containing a known amount of tritium-labelled testosterone (Bio Merieux, Nümbrecht, Germany) in a $\beta$-scintillation counter (Berthold, Bad Wildbad, Germany).

\section{Blood samples}

Blood samples for hormone determinations were drawn between 8.00 and $10.00 \mathrm{~h}$ at two control examinations, shortly before and $1 \mathrm{~h}$ and $1,2,3,5,7$ days after testosterone buciclate injection, and then weekly up to week 16. Blood samples for hormone determinations were separated at $800 \times \mathrm{g}$ and stored at $-20^{\circ} \mathrm{C}$ until assayed.

\section{Immunoassay serum}

SHBG was determined by highly specific fluoroimmunoassay (DELFIA SHBG, Pharmacia GmbH, Freiburg, Germany) $(22,32)$. The detection limit for SHBG was $6.3 \mathrm{nmol} / \mathrm{l}$. The intra- and inter-assay coefficients of variation for SHBG were $5.3 \%$ and $7.2 \%$. In our laboratory the normal range for adult males for SHBG is 11-71 nmol/l. Testosterone and dihydrotestosterone were separated in extracted serum samples by high performance liquid chromatography before measurement by RIA, as described earlier (33). The detection limits for testosterone and dihydrotestosterone were 0.28 and $0.14 \mathrm{nmol} / \mathrm{l}$, respectively. The intra- and inter-assay-coefficients of variation for testosterone were $6.8 \%$ and $9.8 \%$, respectively, and for dihydrotestosterone $8.5 \%$ and $13.4 \%$, respectively. The lower normal limit for androgens (sum of testosterone and dihydrotestosterone) after separation by high performance liquid chromatography was $10 \mathrm{nmol} / \mathrm{l}$ and the upper normal limit for dihydrotestosterone is $2.9 \mathrm{nmol} / \mathrm{l}$ in our laboratory. 


\section{Patients and medication}

The study protocol of the phase I study with testosterone buciclate was approved by the Steering Committee of the WHO Task Force on Methods for the Regulation of Male Fertility, by the WHO Toxicology Group, by the WHO Scientific and Ethical Review Group and by the WHO Secretariat Committee on Research Involving Human Subjects, as well as by the Ethics Committee of the University of Münster and the State Medical Board. Eight adult patients (28-48 years) with primary hypogonadism without additional diseases gave informed consent and were enrolled in the study. After two control examinations the patients were randomly allocated to either of two treatment groups. Two-hundred milligrams of testosterone buciclate $(0.8 \mathrm{ml}$ injection vol, one injection site) were administered by injection to the medial gluteal muscle on day 0 to study group I $(n=4$; age, $37.8 \pm 8.2$ years (mean $\pm S D)$; body weight, $78.2 \pm 12.6 \mathrm{~kg}$; height, $181.7 \pm 5.8 \mathrm{~cm}$ ). Similarly, $600 \mathrm{mg}$ testosterone buciclate $(2.4 \mathrm{ml}$ injection vol, one injection site) were given to study group II $(n=4$; age, $32.3 \pm 3.4$ years; body weight, $84.7 \pm 7.8 \mathrm{~kg}$; height, $183.6 \pm 6.0 \mathrm{~cm}$ ).

The androgen ester testosterone buciclate was prepared by Palmer Research (Holywell, Great Britain) under WHO auspices under Good Manufacturing Practice conditions. After wet milling of crystalline testosterone buciclate obtain at least $75 \%$ of particles in the size range of $10-50 \mu \mathrm{m}$, the drug was sterilized by $\gamma$-radiation and suspended in sterile aqueous solution. The suspension was shaken vigorously for 1 minute before injection. The batch used for all injections had a concentration of $250 \mathrm{~g} / \mathrm{l}$ testosterone buciclate, which corresponds to a concentration of $158.6 \mathrm{~g} / \mathrm{l}(0.55 \mathrm{~mol} / \mathrm{l})$ unesterified testosterone. The clinical data and hormone serum levels of this study have been published elsewhere (21).

\section{Statistical methods}

Variation over time and differences between study groups were evaluated by multifactorial analysis of variance for repeated measures. Computations were performed using statistical software Statview ${ }^{\circledR}$ for Macintosh, version D-4.5, statistical software package SPSS/PC+, version 4.0 (SPSS, Inc., Chicago, IL, USA) and Statgraphics Plus, version 5.2 (STSC, Inc., Rockville, MD, USA). When necessary, variables were logarithmically (log) transformed before analysis to achieve normal distribution. Two sided $p$-values $<0.05$ were considered to indicate significance. In general, results are given as the mean \pm SE.

\section{Results}

\section{Assay characteristics of the new TR-FIA for salivary testosterone}

The new TR-FIA requires as little as $180 \mu$ l of saliva for extraction and triplicate determination, and the assay is easy to handle and takes 6 hours for the determination of 80 samples, including the sample extraction. The testosterone-biotin tracer is stable for at least three years.

\section{Specificity}

The displacing potency of potentially cross-reacting steroids was investigated by addition of increasing doses of steroids as the unknown sample in the immunoassay procedure, and comparison of ED-50. In this assay, $\alpha$-dihydrotestosterone had a relative displacing potency of $19.5 \%$, androstenedione $9.7 \%$, 6- $\beta$-hydroxytestosterone $6.2 \%$, and $11-\beta$-hydroxytestosterone $3.6 \%$.

\section{Sensitivity}

The sensitivity of the TR-FIA was defined as the intercept with the displacement curve of the mean minus two standard deviations of a determination of the zero standard $(n=30)$. The sensitivity was $16 \mathrm{pmol} / \mathrm{l}$.

The mean $50 \%$ intercept of a typical displacement curve was $220 \mathrm{pmol} / \mathrm{l}$.

\section{Imprecision}

The intra-assay coefficients of variation were determined by a measurement of three different saliva samples $(n=36)$ with testosterone concentrations of $302.0 \mathrm{pmol} / \mathrm{l}, 158.5 \mathrm{pmol} / \mathrm{l}$ and $125.0 \mathrm{pmol} / \mathrm{l}$. The intraassay imprecision for the salivary testosterone concentrations of $302 \mathrm{pmol} / \mathrm{l}, 158.5 \mathrm{pmol} / \mathrm{l}$ and $125.0 \mathrm{pmol} / \mathrm{l}$ ( $n=36$ ) was $8.9 \%, 14.6 \%$ and $11.4 \%$, respectively.

Two different samples were determined in 24 consecutive assays for calculation of the inter-assay imprecision. The inter-assay coefficient of variation for the concentrations of $182.4 \mathrm{pmol} / \mathrm{l}$ and $304.8 \mathrm{pmol} / \mathrm{l}$ was $7.9 \%$ and $8.7 \%$, respectively $(n=24)$.

\section{Recovery}

The mean recovery of the extraction step was $93 \%$ (for $n=12$ ).

Salivary samples with testosterone concentrations of $236.5 \mathrm{pmol} / \mathrm{l}, 210.5 \mathrm{pmol} / \mathrm{l}, 182.0 \mathrm{pmol} / \mathrm{l}$ and 131.1 $\mathrm{pmol} / \mathrm{l}$ were serially diluted with zero-standard. The measured concentrations were compared with the expected concentrations and expressed as a percentage of the expected value. The mean recoveries were $104.1 \%, 94.2 \%, 93.6 \%$, and $95.6 \%$, respectively.

\section{Correlation of salivary testosterone TR-FIA with RIA}

Salivary samples $(n=132$, concentration range: $37 \mathrm{pmol} / \mathrm{l}$ - $403 \mathrm{pmol} / \mathrm{l}$ ) from healthy men and women were analyzed using both the established RIA adapted for salivary testosterone measurement and the new TR-FIA. The correlation found was significant $(r=0.89$, $\mathrm{p}<0.0001$ ) (Fig. 2)

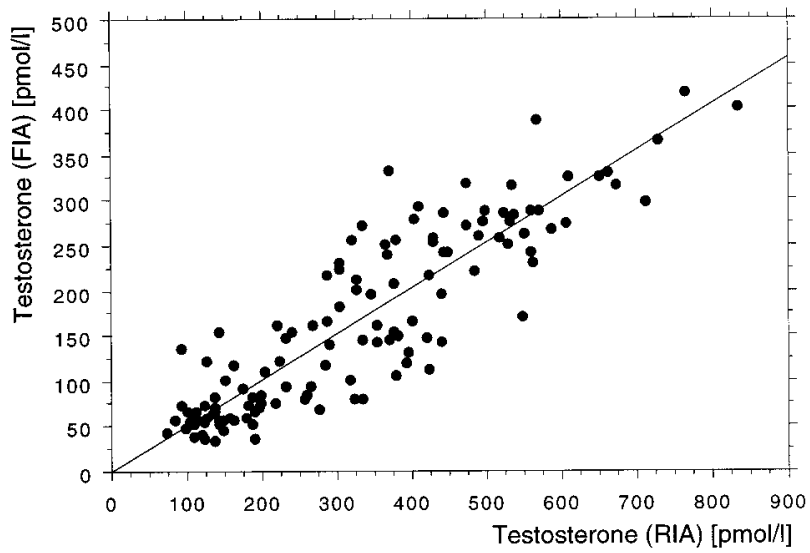

Fig. 2 Comparison of the new time-resolved fluorescence immunoassay (TR-FIA) and an established radioimmunoassay (RIA) (31) for the measurement of testosterone in saliva regression analysis: $y=1.076+0.505 x ; r=0.89 ; p<0.0001(n=132$ salivary samples; concentration range: $37 \mathrm{pmol} / \mathrm{l}-403 \mathrm{pmol} / \mathrm{l}$ ). 
Monitoring of testosterone replacement therapy in hypogonadal men in saliva

After injection of $600 \mathrm{mg}$ testosterone buciclate, salivary testosterone increased from $203 \pm 36 \mathrm{pmol} / \mathrm{l}$ (mean $\pm \mathrm{SE}$ ) to $303 \pm 18 \mathrm{pmol} / \mathrm{l}$ (mean $\pm \mathrm{SE}$ ) and was maintained in the normal range $(230 \mathrm{pmol} / \mathrm{l}-570 \mathrm{pmol} / \mathrm{l}$ as validated for the TR-FIA) for up to eleven weeks. However, after injection of 200 mg testosterone buciclate, salivary testosterone did not increase significantly. The time course of increase of salivary testosterone was parallel to that of serum androgen levels for both groups. (Fig. 3)
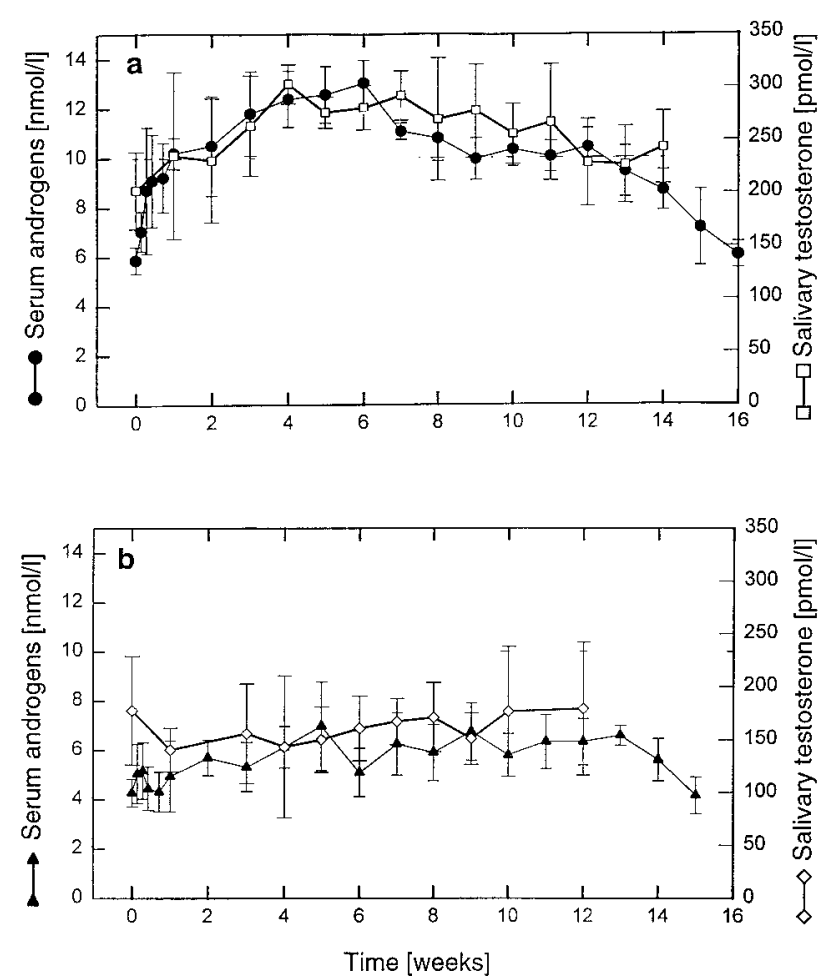

Fig. 3 Salivary testosterone concentrations and serum androgen (sum of serum testosterone and serum dihydrotestosterone concentrations) levels in hypogonadal men after injection of testosterone buciclate $(\mathrm{a} ; 600 \mathrm{mg}$ testosterone buciclate, $n=4)(b ; 200 \mathrm{mg}$ testosterone buciclate $n=4)$.

Correlation of salivary testosterone concentration with serum SHBG, oestradiol, dihydrotestosterone and testosterone

The salivary testosterone levels measured after injection of testosterone buciclate showed a negative correlation with SHBG in serum ( $r=0.50 ; p \varangle 0.001)$, a positive correlation with serum oestradiol ( $r=0.52 ; p<0.001)$, a positive correlation with serum dihydrotestosterone $(r=0.37 ; p<0.001)$ and a weak, but significant, correlation with total serum testosterone $(r=0.22 ; p=0.009)$.

\section{Discussion}

We have established a new method for the measurement of salivary testosterone and used it for the moni- toring of testosterone replacement therapy with the androgen ester testosterone buciclate in eight hypogonadal men.

When multiple sampling is required, as in the monitoring of testosterone replacement therapy, salivary hormone measurement is non-invasive and stressfree. The methods are accurate and reliable. (34). Frequent collecting and mailing of saliva samples is practicable for the patients and does not require assistance of medically trained staff (25).

The newly established TR-FIA is characterized by a number of advantageous features. A sample volume of not more than $180 \mu$ l of saliva was sufficient for the accurate measurement of salivary testosterone, while comparable methods $(28,31)$ require a sample volume between $500 \mu \mathrm{l}$ and $5000 \mu \mathrm{l}$. The non-isotopic method is easy to perform, inexpensive, takes a total of three hours incubation time and has a lower detection limit of $16 \mathrm{pmol} / \mathrm{l}$. Sensitivity and accuracy of this assay should allow the measurement of salivary testosterone in women and even pre-pubertal children. Correlation with an established assay was good ( $r=0.89$ ). A slope of the regression line of only $b=0.51$ is most probable due to the use of different standards. The employed biotintestosterone conjugate has a molecular size weight of 740.5 Da which is comparable with the analyzed steroid (288.4 Da) and can be stored for more than 24 months without significant loss of activity. The use of biotin as a primary probe provides a signal amplification system (23) and also has the advantage of a versatile endpoint determination: this tracer can be detected using EIA readers, TR-fluorometers, luminometers or in conventional $\gamma$-counting, thereby reducing between-laboratory variance. The antibody used is highly specific. The assay procedure is simple, reliable and rapid.

Testosterone in serum is largely bound to SHBG and albumin. The unbound testosterone and corticosteroid-binding globulin-bound testosterone fractions are minimal. The unbound testosterone is biologically active, while SHBG-bound testosterone is not. The bioavailability of albumin-bound testosterone is controversial (35-37), but some studies suggest that bioavailable testosterone includes circulating free testosterone and a large proportion of albumin-bound testosterone $(6,38)$. An argument in favour of this theory is that the half-dissociation time of testosterone from SHBG is relatively long ( $\angle 20 \mathrm{sec}$ ), while in contrast, the half-dissociation time of testosterone from albumin $(<1 \mathrm{sec})$ is within the probable capillary transit time. Therefore these fractions may be available to target tissues and saliva, respectively. Salivary testosterone levels are independent of salivary flow rate (5) and, due to the rapid passage of steroid hormones from blood to saliva, despite enzymes such as 5 - $\alpha$-reductase being present in salivary glands (39), steroid metabolism is probably not an important source of error in the measurements of testosterone in saliva (40). The importance of metabolism of testosterone in salivary glands is still unclear $(41,42)$, but recent results of in vitro experiments (40) and the excellent correlation of salivary tes- 
tosterone with total-, free- and particularly non-SHBGbound testosterone (16), suggest that metabolism of steroids in human salivary glands does not affect the level of salivary testosterone. Thus, salivary testosterone appears to reflect the biological activity of the hormone.

Development of accurate assays for analytes present at low picomolar concentrations in body fluids is a demanding task. The appearance of an unexpected positive bias in salivary testosterone assays which was dependent on the material chosen for saliva sampling is an example of the encountered difficulties. In this context we could confirm earlier results of Dabbs (28), who detected testosterone-like immunoreactivity in cotton wool swabs used in saliva sampling devices. In search for an optimal method of saliva sampling for the testosterone TR-FIA, the eluates from three of the existing types of "salivettes" were measured. These were soaked with $1 \mathrm{ml}$ of saline under sterile conditions, frozen, thawed and centrifuged as described above for the pretreatment of salivary testosterone samples. In two of the extracted eluates we found testosterone concentrations in a range corresponding to normal male levels in saliva. The testosterone-like immunoreactivity was detectable even after organic extraction, supporting the hypothesis that the nature of this immunoreactivity is similar to that of other steroid hormones. Only one type of salivette, which did not contain glue and was not prepared with citric acid for the stimulation of salivary flow, did not demonstrate significant testosterone-like immunoreactivity.

In futher experiments we compared this sampling method to direct sampling in a glass tube. Forty-eight medical students tested both sampling methods, one method immediately following the other. The sampling method using the salivettes led to lower matrix effects (i.e. contamination with food particles) than the direct colecting of saliva in a glass tube. In addition, most of the volunteers felt the salivettes to be a more comfortable and more hygienic sampling method.

Up to now the achievement of constant serum levels in a physiological range has been the main pharmaco-kinetic goal when searching for new testosterone preparations. Salivary testosterone reflects the bioactive testosterone fraction $(1,2,38,43,44)$. The measurement of this variable is of interest as a meaningful criterion for the effectiveness of an androgen preparation.

Due to the close link between sperm production and male hormones, endocrinological suppression of sperm production is parallel with suppression of androgen production. Thus androgen replacement therapy plays an important role in the development of methods for male contraception.

This study confirms both the adequacy of measurement of salivary testosterone as a monitoring system and testosterone buciclate as an androgen ester with desirable pharmacokinetics for testosterone replacement therapy: after administration of testosterone buciclate the course of the salivary testosterone curve and the serum testosterone curve behaved similarly.
Both salivary testosterone and serum testosterone increased to normal levels and were maintained in a physiological range for seven weeks after a single injection of $600 \mathrm{mg}$ of testosterone buciclate. After administration of $200 \mathrm{mg}$ of testosterone buciclate, however, salivary testosterone levels as well as serum testosterone levels did not increase (Fig. 2).

A negative correlation of salivary testosterone with serum SHBG reflects the important role of circulating SHBG on the amount of biologically active testosterone and salivary testosterone. According to the thesis that only the non-SHBG-bound testosterone is bioactive and reflected by salivary testosterone, high SHBGlevels are associated with low salivary testosterone levels and vice versa. Furthermore, a positive correlation between salivary testosterone and serum oestradiol, which is one of the co-regulators of SHBG synthesis in the liver, could be explained by a displacement of bound androgens by increasing levels of oestradiol and vice versa.

In summary, we have established a new method for the measurement of testosterone in saliva using the streptavidin-biotin tracer as a tool. The new ultrasensitive method is fast, non-isotopic and requires a sample volume of not more than $180 \mu \mathrm{l}$ for extraction and duplicate determination. In addition, the new TR-FIA was applied to a clinical phase I study, in which the new long-acting androgen ester, testosterone buciclate, was tested as a substitution therapy for male hypogonadism. Its favourable pharmacodynamics and pharmacokinetics, as shown previously by monitoring testosterone in serum (21), were confirmed by monitoring its bioactive fraction by multiple consecutive measurements of salivary testosterone.

\section{Acknowledgements}

The authors would like to thank Susan Nieschlag, M.A. for language editing of the manuscript. We are grateful to Prof. Dr. Dr. Frank Bidlingmaier (Bonn) for the supply of testosterone antiserum.

\section{References}

1. Osredkar J , Vrhovec I, J esenovec N, Kocijancic A, Prezelj J . Salivary free testosterone in hirsutism. Ann Clin Biochem 1989; 26:522-6.

2. Vittek J, L'Hommedieu DG, Gordon GG, Rappaport SC, Southren AL. Direct radioimmunoassay (RIA) of salivary testosterone: correlation with free and total serum testosterone. Life Sci 1985; 37:711-6.

3. Baxendale PM, J acobs HS, J ames VH. Salivary testosterone: relationship to unbound plasma testosterone in normal and hyperandrogenic women. Clin Endocrinol (Oxf) 1982; 16:595-603.

4. Riad-Fahmy D, Read GF, Walker RF, Griffiths K. Steroids in saliva for assessing endocrine function. Endocr Rev 1982; 3:367-95.

5. Ferguson DB. Physiological considerations in the use of salivary steroid estimation for clinical investigations. Basel: Karger, 1984; 5:1-20. 
6. Manni A, Pardridge WM, Cefalu W, Nisula BC, Bardin CW, Santner SJ , et al. Bioavailability of albumin-bound testosterone. J Clin Endocrinol Metab 1985; 61:705-10.

7. Magrini G, Chiodoni G, Rey F, Felber J P. Further evidence for the usefulness of the salivary testosterone radioimmunoassay in the assessment of androgenicity in man in basal and stimulated conditions. Horm Res 1986; 23:65-73.

8. Wang C, Plymate S, Nieschlag E, Paulsen CA. Salivary testosterone in men: further evidence of a direct correlation with free serum testosterone. J Clin Endocrinal Metab 1981; 53:1021-4.

9. Heyns W, De Moor P. Kinetics of dissociation of 17-beta-hydroxysteroids from the steroid binding beta-globulin of human plasma. J Clin Endocrinol Metab 1971; 32:147-54.

10. Cefalu W, Pardridge W, Chaudhuri G, J udd H. Serum bioavailability and tissue metabolism of testosterone and estradiol in rat salivary gland. J Clin Endocrinol Metab 1986; 63:20-8.

11. Dabbs J M J r. Salivary testosterone measurements in behavioral studies. Ann N Y Acad Sci 1993; 694:177-83.

12. McCaul KD, Gladue BA, J oppa M. Winning, losing, mood, and testosterone. Horm Behav 1992; 26:486-504.

13. Christiansen K. Sex hormone-related variations of cognitive performance in Kung San hunter-gatherers of Namibia. Neuropsychobiology 1993; 27:97-107.

14. Beall CM, Worthman CM, Stallings J , Strohl KP, Brittenham GM, Barragan M. Salivary testosterone concentration of Aymara men native to 3600 m. Ann Hum Biol 1992; 19:67-78.

15. Lipson SF, Ellison PT. Development of protocols for the application of salivary steroid analysis to field conditions. Am J Hum Biol 1989; 1:249-55.

16. Ruutiainen K, Sannikka E, Santti R, Erkkola R, Adlercreutz H. Salivary testosterone in hirsutism: correlations with serum testosterone and the degree of hair growth. J Clin Endocrinol Metab 1987; 64:1015-20.

17. Wilchek M, Bayer EA. Introduction to avidin-biotin technology. In: Wilchek M, Bayer EA, editors. Methods in enzymology. New York: Academic Press. 1990:5-13.

18. Bardin CW, Swerdloff RS, Santen RJ . Androgens: risks and benefits. J Clin Endocrinol Metab 1991; 73:4-7.

19. Nieschlag E, Behre HM, Weinbauer GF. Perspectives in andrology. Serono Symposia. New York: Raven Press, 1989:517-29.

20. WHO Task Force on methods for the regulation of male fertility. Contraceptive efficacy of testosterone-induced azoospermia in normal men. Lancet 1990; 336:955-9.

21. Behre HM, Nieschlag E. Testosterone buciclate (20 Aet-1) in hypogonadal men: pharmacokinetics and pharmacodynamics of the new long-acting androgen ester.J Clin Endocrinol Metab 1992; 75:1204-10.

22. Behre HM, Baus S, Kliesch S, Keck C, Simoni M, Nieschlag E. Potential of testosterone buciclate for male contraception: endocrine differences between responders and nonresponders. J Clin Endocrinol Metab 1995, 80:2394-403.

23. Strasburger CJ , Amir-Zaltsman Y, Kohen F. The avidin-biotin reaction as a universal amplification system in immunoassays. In: Albertson BD, Haseltine FP, Alan R, editors. Non radiometric assays: technology and application in polypeptide and steroid hormone detection. New York: Liss Inc., 1984:79-100.

24. Dressendorfer RA, Kirschbaum C, Rohde W, Stahl F, Strasburger CJ. Synthesis of a cortisol-biotin conjugate and evaluation as a tracer in an immunoassay for salivary cortisol measurement. J Steroid Biochem Mol Biol 1992; 43:683-92.

25. Dabbs J M J r. Salivary testosterone measurements: col- lecting, storing, and mailing saliva samples. Physiol Behav 1991; 49:815-7.

26. Tschöp M, Dressendörfer RA, Strasburger CJ . Reliability of saliva sampling devices in salivary testosterone assays. Exp Clin Endocrinol 1993; 101:178.

27. Schramm W, Smith RH, Craig PA, Grates HE. Testosterone concentration is increased in whole saliva, but not in ultrafiltrate, after toothbrushing. Clin Chem 1993; 39:519-21.

28. Dabbs J M J r. Salivary testosterone measurements: reliability across hours, days, and weeks. Physiol Behav 1990; 48:83-6.

29. Meulenberg EP, Hofman J A. The effect of pretreatment of saliva on steroid hormone concentrations. J Clin Chem Clin Biochem 1990; 28:923-8.

30. Soini E. Pulsed light, time-resolved fluorometric immunoassay. In: Bizollon CA, editor. Monoclonal antibodies and new trends in immunoassays. Amsterdam: Elsevier, 1984:197-208.

31. Schürmeyer T, Wickings EJ , Freischem CW, Nieschlag E. Saliva and serum testosterone following oral testosterone undecanoate administration in normal and hypogonadal men. Acta Endocrinol (Copenh) 1983; 102:456-62.

32. Behre HM, Nashan D, Hubert W, Nieschlag E. Depot gonadotropin-releasing hormone agonist blunts the androgeninduced suppression of spermatogenesis in a clinical trial of male contraception. J Clin Endocrinol Metab 1992; 74:84-90.

33. Bals-Pratsch M, Langer K, Place VA, Nieschlag E. Substitution therapy of hypogonadal men with transdermal testosterone over one year. Acta Endocrinol (Copenh) 1988; 118:7-13.

34. Dabbs J M J r, Campbell BC, Gladue BA, Midgley AR, Navarro MA, Read GF, et al. Reliability of salivary testosterone measurements: a multicenter evaluation. Clin Chem 1995; 41:1581-4.

35. Smith RG, Besch PK, Dill B, Buttram VC J r. Saliva as a matrix for measuring free androgens: comparison with serum androgens in polycystic ovarian disease. Fertil Steril 1979; 31:513-7.

36. Lea OA, Stoa KF. The binding of testosterone to different serum proteins: a comparative study. J Steroid Biochem 1972; 3:409-19.

37. Blight LF, J udd SJ , White GH. Relative diagnostic value of serum non-SHBG-bound testosterone, free androgen index and free testosterone in the assessment of mild to moderate hirsutism. Ann Clin Biochem 1989; 26:311-6.

38. Cumming DC, Wall SR. Non-sex hormone-binding globulin-bound testosterone as a marker for hyperandrogenism. J Clin Endocrinol Metab 1985; 61:873-6.

39. Migliardi CM, Cenderelli G, Godano G. Androgen metabolism in the human salivary glands. J steroid biochem 1986, 25 (Supp 145):14.

40. Blom T, Ojanotko-Harri A, Laine M, Huhtaniemi I. Metabolism of progesterone and testosterone in human parotoid and submandibular salivary glands in vitro. J Steroid Biochem Mol Biol 1993; 44:69-76.

41. Swinkels LM, van Hoof HJ , Ross HA, Smals AG, Benraad TJ . Concentrations of salivary testosterone and plasma total, non-sex-hormone-binding globulin-bound, and free testosterone in normal and hirsute women during administration of dexamethasone/synthetic corticotropin. Clin Chem 1991; 37:180-5.

42. Pardridge WM, Demers LM. Bioavailable testosterone in salivary glands [editorial; comment]. Clin Chem 1991; 37:139-40.

43. Wellen J J , Smals AG, Rijken J C, Kloppenborg PW, Benraad $\mathrm{TJ}$. Testosterone and delta 4-androstenedione in the 
saliva of patients with Klinefelter's syndrome. Clin Endocrinol (Oxf) 1983; 18:51-9.

44. Swinkels LM, Meulenberg PM, Ross HA, Benraad TJ . Salivary and plasma free testosterone and androstenedione levels in women using oral contraceptives containing desogestrel or levonorgestrel. Ann Clin Biochem 1988; 25:354-9.

Received 10 October 1997; accepted 11 March 1998
Corresponding author: Matthias Tschöp,

AG Neuroendokrinologie, Medizinische Klinik, Klinikum Innenstadt der Ludwig Maximilians Universität, Ziemssenstr. 1, D-80336 München, Germany

Tel.: +49-89-5160-2246, Fax: +49-89-5160-4566

E-mail: Tschoep @ medinn.med.uni-muenchen.de 